\title{
Public Space: Activation v. De-Activation
}

\section{CLIFTON C. ELLIS}

Texas Tech University

Historically, the great cities of the world have built public spaces that have often been used as venues for spectacle, and displays of power and status. These public venues are part of the identity of these cities and have an importance and influence far beyond their physical dimensions or geometric shapes. They are all platforms that accommodate, both physically and metaphorically, the various expressions of a society. This paper will address historical events and their transcendency within the context of the city and their historical importance and effect in a larger global context. In addition, it will apply theoretical concepts about city space and the public sphere through an application of post-structuralist theory, critical theory, and social capital theory. ${ }^{1}$

As Deluze has noted, events have the tendency to be the stimuli that reshape the conceptual connectivity, relationships, path-ways and institutions in which these events take place. Therefore, the relationships between the actors and the public space creates activation and deactivation. For Deleuze, events begin from the domain of an idea / axiom and the virtual (temporal) but events are only actualized in that space. ${ }^{2}$

These public realms, these "platforms," are subject to direct activation and indirect and censored deactivation. Public space is active everyday by individuals and groups and for various purposes; however, activation of public space takes

\author{
DAVID J. ISERN \\ Texas Tech University
}

place when a direct action is inposed on the space without any filter or censorship. In this paper, we examine the activation of a public space as a platform for political expression. The deactivation of a space, therefore, is the suppression of political expression.

The public space, which we're calling "platforms," can be thought of in three distinct ways (figure 1), which can have different levels of public activation:

1. Space as a platform with defined boundaries;

2. Space as a non-physical platform with no defined boundaries;

3. Space as a physical platform with no boundaries.

\section{SPACE AS A PLATFORM WITH DEFINED BOUNDARIES}

An example of space as a platform with defined boundaries is Beijing's Tiananmen Square, which today comprises a vast 109 acres, capable of holding approximately 500,000 thousand people. Tiananmen means "Gate of Heavenly Peace," and the square was named for the gate on its north side that separates the square from the Imperial City, which surrounds the Forbidden City at its center. The Tiananmen Gate was built in 1415 during the Ming Dynasty and became the main entrance to the Imperial City. In 1651, the new Qiing Dynasty built a large walled square of approximately 25 acres in front
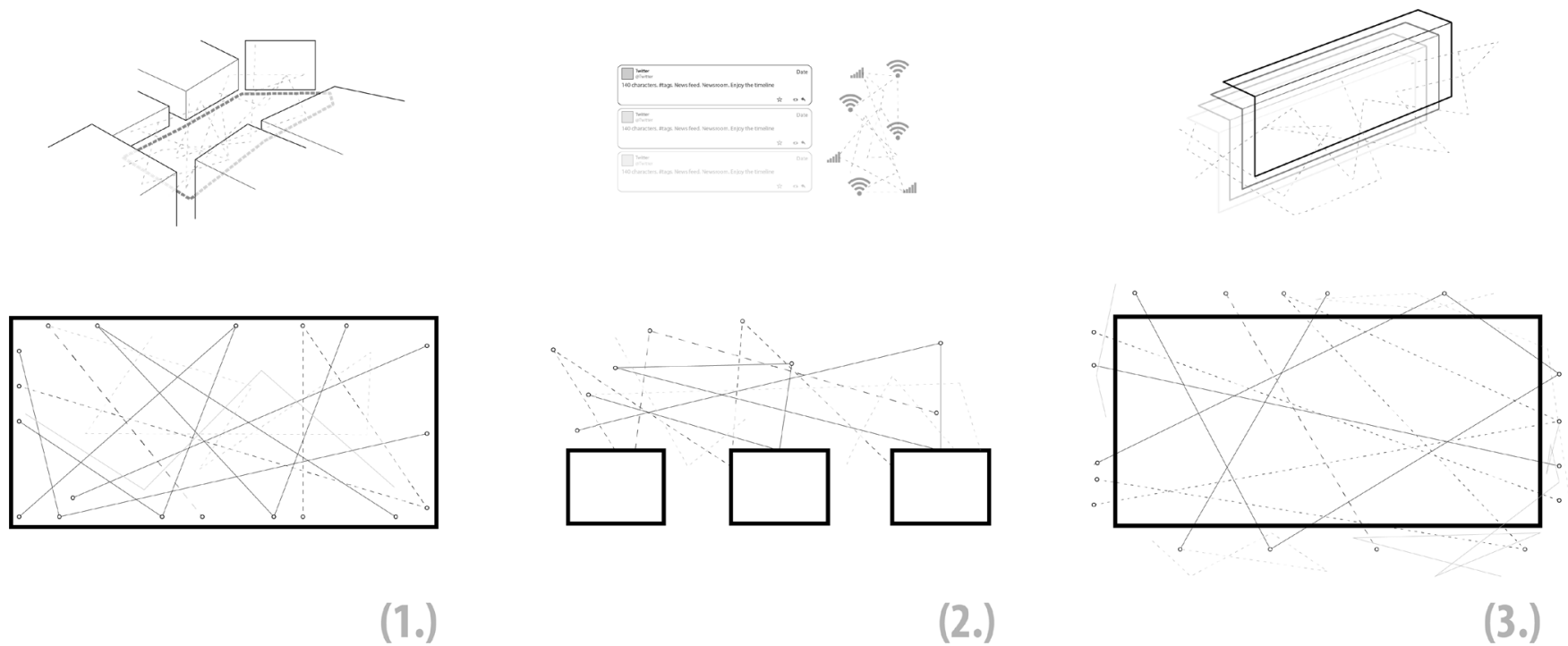

Figure 1:Diagram dipicting forms of public space and the methods of public activation 
of the Tiananmen Gate with a monumental ceremonial gate in the south wall, directly on axis with the Tiananmen Gate. This ceremonial gate, called the China Gate, had three arched openings and was the terminus to a long, narrow, walled processional route. The beginning of the route was itself marked by another gate, the battlemented Great Qianmen Gate. This new series of spaces was roughly the shape of a " $\mathrm{T}$ " (see diagram) and provided a formal route for the highly ritualized processions of the Emperor and Empress. Tiananmen Square was used originally only for ceremonies performed by the Emperor as a means of legitimizing his power and reinforcing the divine nature of his position. The ceremonies were witnessed by his court and dignitaries, but commoners were never allowed in the square. ${ }^{3}$

In 1911, the Qing Dynasty was overthrown, ending 2,000years of Imperial China and establishing The Republic of China. With that event, the east and west gates of Tiananmen Square were opened to the city, and commoners, who had been excluded from the Square since its inception in 1641, were allowed to enter and look upon the great Tiananmen Gate. The square became the center for public gatherings of both celebration and protest, and in this way began the history of political activations and deactivations of the square. The most notable of these activations being the May Fourth Movement of 1919, an anti-imperialist protest led by students who objected to the Treaty of Versailles, by which Germany ceded China's Shandong province to Japan, and the proclamation of the People's Republic of China by Mao Zedong on October 1, 1949, marking the victory of Mao's communist forces over the nationalist forces of Chiang Kai-Shek. ${ }^{4}$

In 1954, Mao Zedong enlarged Tiananmen Square, multiplying its area by four times. On the west side of the square Mao built the Great Hall of the People, and to the east he built the National Museum of China. During the process, the historic three-arched Gate of China was demolished upon the advice of Soviet Russia officials. ${ }^{5}$

This monumental space is now a rectangle with defined boundaries and the Chinese government uses it as a place to display its military power, with troops and military equipment arranged in strict geometric order, complementing the geometric organization of the square. This formal public space, together with the formal arrangement of the troops is the manifestation of the power of the government and its choreographed spectacle that is meant to awe and to intimidate spectators.

In the late 20th century, Tiananmen Square became associated with the 1989 "Democracy Demonstrations" in which hundreds of thousands of Chinese university students protested for democratization of the communist government. In Post-Mao China, the highly centralized and autocratic government began to move cautiously toward a free market economy, albeit limited. Although most Chinese welcomed a

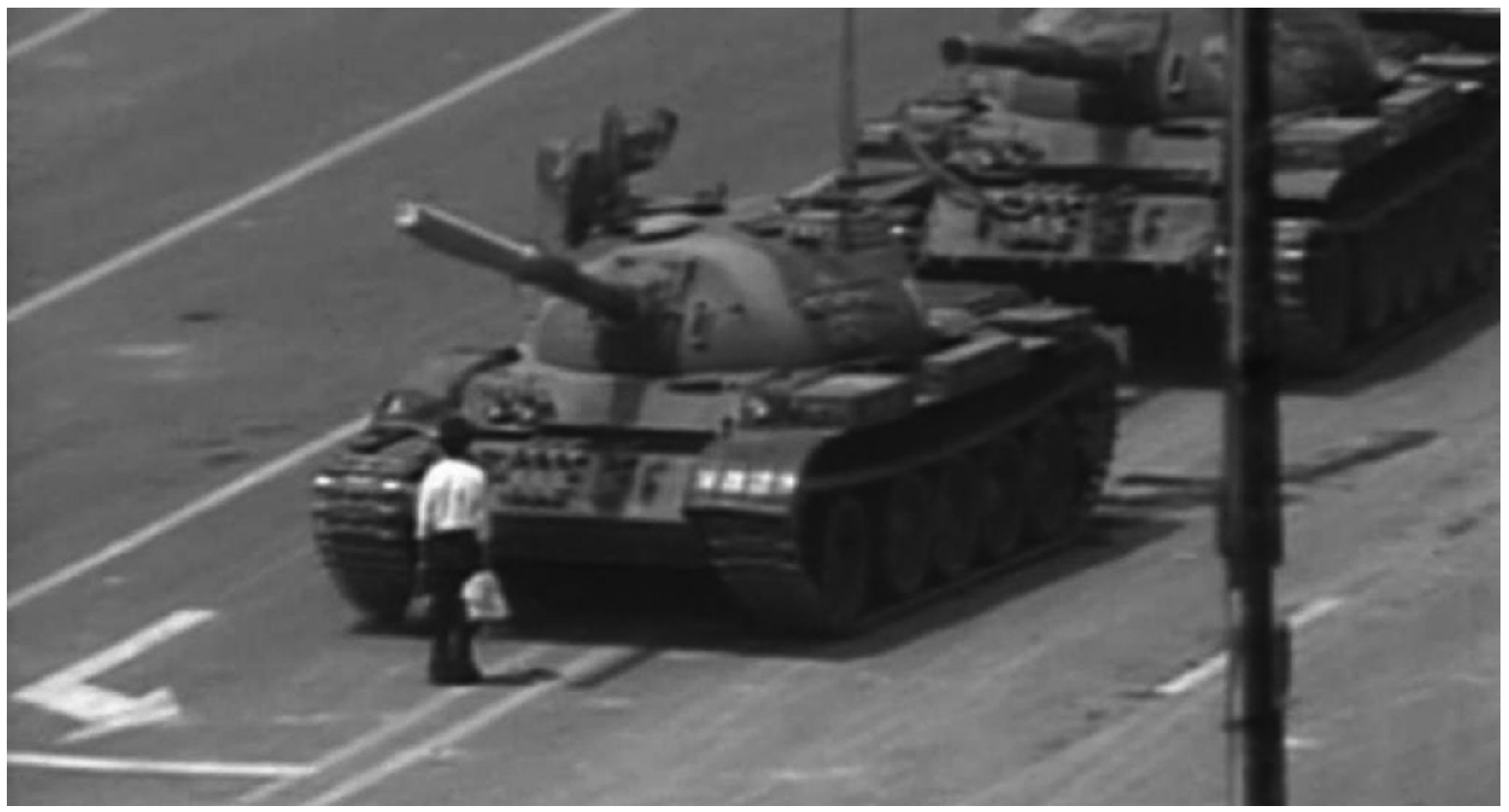

Figure 2: Jeff Widener's photograph of one protestor, the lone “Tank Man”in Tiananmen Square, June 5, 1989. 


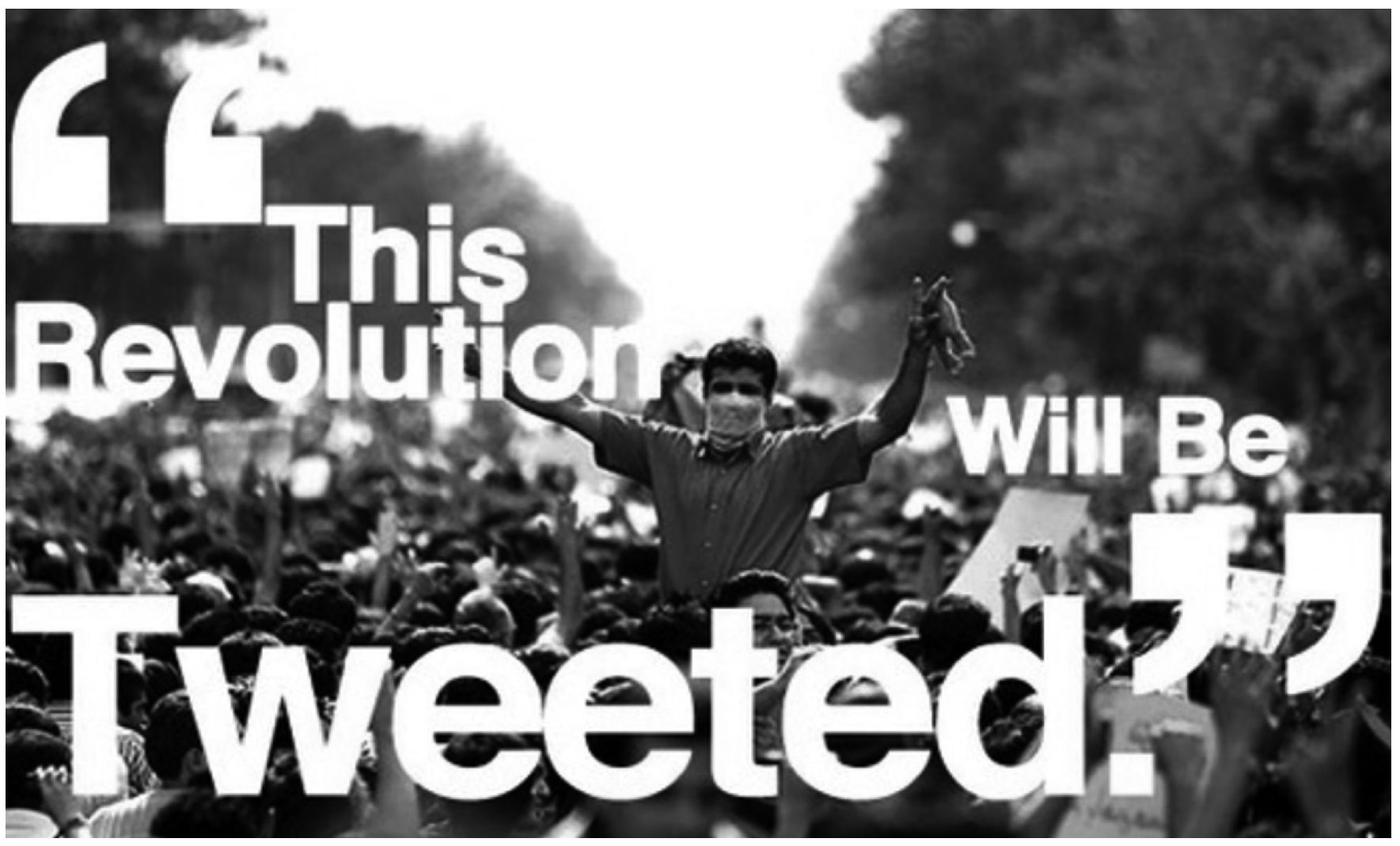

Figure 3: Arab Spring social media post demonstrating the power of people and the use Twitter, c.2011.

more open economy, it proved a disadvantage to many people, causing anxiety and political unrest. University students in particular were concerned that their education provided no preparation to compete in a freer market place. Inflation and restrictions on political participation caused students to take to the streets in protest, with Tiananmen Square as their destination. In response to this huge gathering of students, the government filled the square with tanks and soldiers that moved in orderly unison until one man confronted a tank, causing it to stop in its tracks. ${ }^{6}$

The evocative and iconic photo, taken June 5 by Jeff Widener, is the famous image of the one protestor, the lone "Tank Man," who confronted the tank. In that moment "Tank Man" activated the physical space with his actions of protest. $^{7}$

The choreographed parades of Chinese political leaders are not so much an activation of the space, but rather more of a utilization of the space for a coercive spectacle of autocratic power. Tiananmen Square has been an historic and symbolic space throughout Chinese history. Whoever occupies this space acquires an authority, a legitimacy. The protesters activated the space with a chaotic demonstration of dissatisfaction with the Chinese government. They were no longer simply a passive audience watching the choreographed moves of soldiers and weaponry. When the government sent in the tanks, their intent was to de-activate the space by turning it once again into a place of choreographed spectacle. The tank man co-opted the space by disrupting this spectacle. His act of defiance activated the space in a democratic display of protest.

Although the tank incident was known almost immediately around the world, the Chinese government suppressed images and news of the incident. In effect, the event did not happen, as expressed by Louisa Lim who in her book "The People's Republic of Amnesia: Tiananmen Revisited" stated that initially the regime "enforce[ed] amnesia and whitewash[ed] its own history" of the protest and the lone "Tank Man." ${ }^{\prime \prime}$ It could be said that despite "Tank Man's" activation of the space, the public space was de-activated by hostile powers.'

The edited, filtered message of the choreographed becomes a deactivator, which is disrupted by immediate, un-edited, un-filtered actions of the disrupter who re-activates the space. In the Tiananmen Square protests, activation and Deactivation met face-to-face. The choreographed met its disruptor - the chaotic.

SPACE AS A NON-PHYSICAL PLATFORM WITH NO 


\section{DEFINED BOUNDARIES}

An example of space as a non-physical platform with no defined boundaries is the Arab Spring movements. In these cases, social media is its own public space. Social Media has become the ubiquitous method of communication, networking, and spreading of ideas. For Habermas the public sphere was not confined to identifiable, physical spaces such as the seventeenth-century coffee house of London. The public sphere was also a virtual community that carried ideas through time and space and which could be accessed through the intellectual climate of the day. ${ }^{10}$

Although Habermas didn't anticipate Twitter, he would recognize that digital technology, without physical form itself, does indeed give form and animates that form by harnessing the powers inherent in its medium.

Facebook and Twitter both generate and activate a public 'space' that seemingly exists in the ether - until it is summoned and activated by anonymous choreographers who eventually give it a physical manifestation or a 'will' that morphs into physical form, dimension, and geometry. The twitter user is a lone actor within a non-physical space - a fiat space - that gives agency to those who will activate a physical public space. The twitter user becomes a catalyst to the creation of an actual space by allowing multiple actors to define a physical space for protest or celebration.

Figure 4 is a diagram explaining how ideas compete in the virtual platform. Idea 1 and Idea 2 are in dispute. Idea 1 first activates a platform. Then Idea 2 challenges Idea 1 and deactivates the platform, thereby becoming an activator itself.

The conflict of ideas that generated within the platform is what activates or deactivates the space. The deactivators become the activators, but only from the perspective of the original activators. This emulation of ideas is what leads to their physical manifestations, and the direct activation of the public sphere. Moreover, this conflict becomes an ideological dispute that, when it happens in the platforms, it becomes significant and justifies the needs both historically and for the future of public space.

The Arab Spring, for example, was a revolutionary wave of protests, riots, coups, and civil wars that swept North Africa and Middle East between December 2010 and July 2012. The use of social media platforms, especially Facebook, more than doubled during this period. Most importantly this
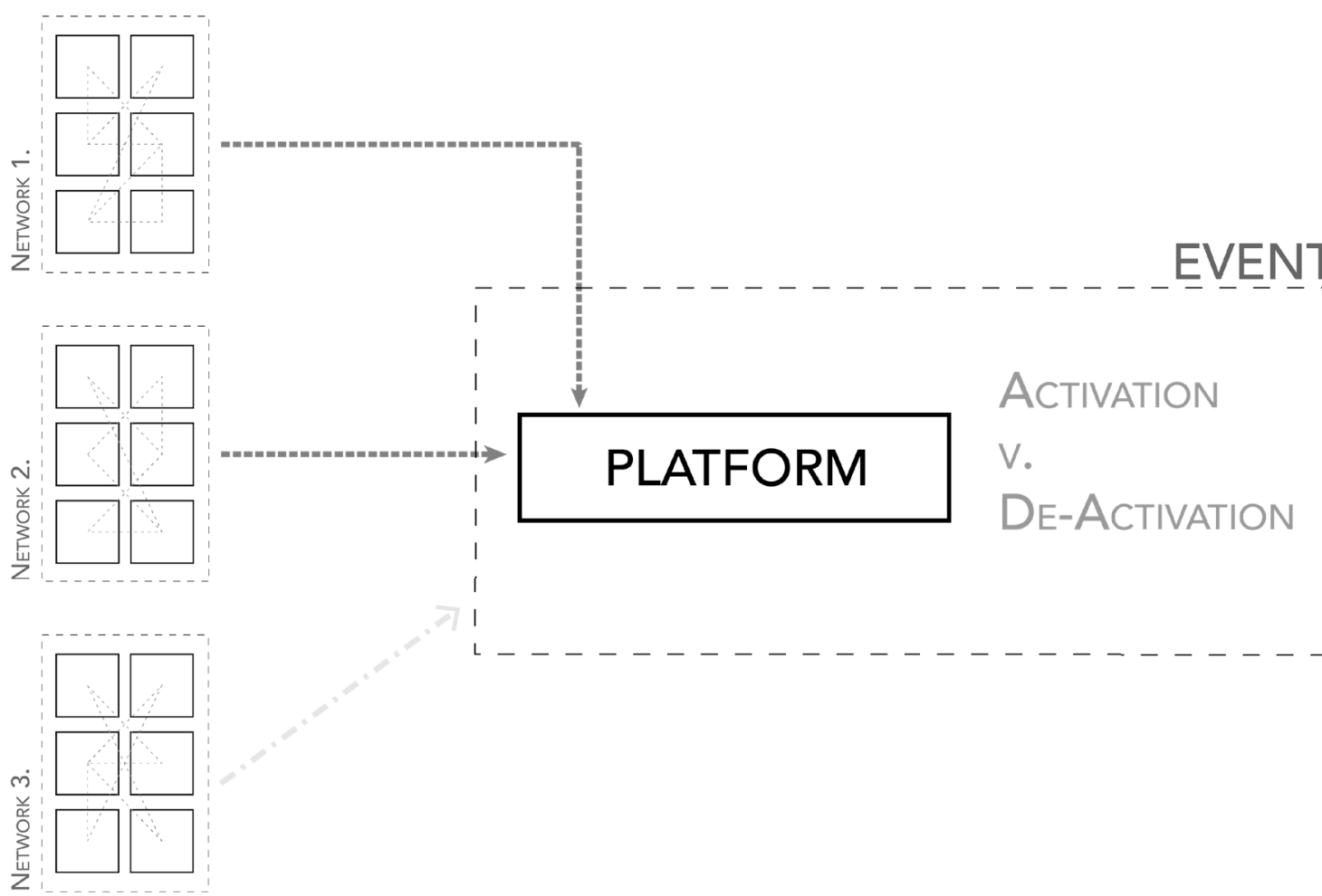

L

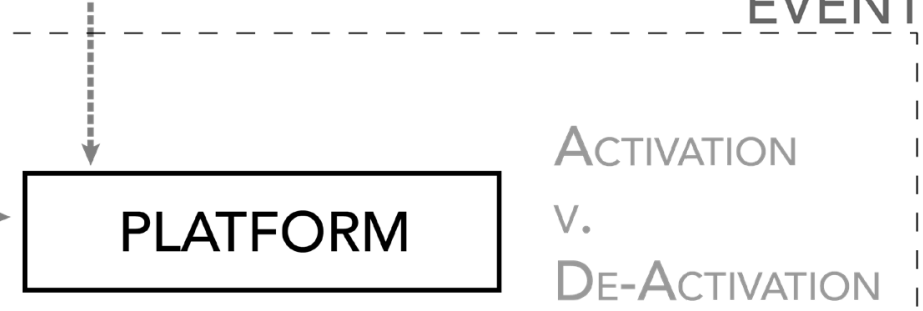


virtual platform was able to provide the actors with a methods of activation that the government and the de-activators have very little control over, making the action of activation crucial for all individuals and their contribution and decision making towards the collective good. Moreover, this activation, regardless of perspective, is based on the immediacy of the actions and their physical manifestation or effects on the public space.

The term Arab Spring is a reference to the 1848 Revolutions in Europe, which contemporaries of the time called "the spring time of Nations." Like the 1848 Revolutions, the Arab Spring was caused by a variety of factors and combinations of factors such as authoritarianism, political corruption, human rights violations, poverty, unemployment, and inflation, to name a few. ${ }^{11}$

The protests began in Tunisia and were a response to the selfimmolation of Mohamed Bouazizi on 17 December 2010. The 26-year-old Bouazizi street vendor was driven to suicide by a lifetime of systematic abuse and humiliation by petit bureaucrats who thrived under the autocratic regime of Tunisian President Zine El Abidine Ben Ali. On the day of his selfimmolation, inspectors of the local market in Bouazizi's town harassed Bouazizi for not having a vendor's permit, although no permits are required for cart vendors like Bouazizi whose cart was filled with vegetables. The inspectors confiscated Bouazizi's produce, his scales, and his cart. Bouazizi went to the local governor's office to report the incident but was turned away, at which point Bouazizi walked to a nearby service station and bought the gas with which he lit himself afire. Bouazizi died 18 days later, on January $4 .{ }^{12}$

The peoples' reaction to Bouazizi's death was immediate and widespread. On January 2011, Tunisians began protests and demonstrations that quickly ousted president Zine EI Abidine Ben Ali who had taken over the presidency in a bloodless coup d'état in 1987. Ben Ali's imprisonment of political opponents, his secret police and general corruption, along with social inequity, and unemployment incited a concerted campaign to bring down his government. After a remarkably short four-week-long protest movement, Ben Ali resigned as President of Tunisia, but only after he had been refused asylum by France and then granted it by Saudi Arabia on the condition that he not participate in any kind of media or politics. Ben Ali's 23-year rule ended and the Arab Spring began. ${ }^{13}$

Thanks primarily to the efforts of the Tunisian National Dialogue Quartet, a coalition of two unions and two advocacy groups, a democratic republic was reinstated with free elections held by 2013. The Quartet received the Nobel Peace Prize in 2015 for "its decisive contribution to the building of a pluralistic democracy in Tunisia in the wake of the Tunisian Revolution of 2011."14

The Tunisian Revolution inspired similar attempts at political change in Libya, Egypt, Yemen, Syria, and Bahrain. Protestors throughout the North Africa and the Middle East raised signs and hung banners that proclaimed "The people want to bring down the regime." Riots and street violence in each of the other countries achieved various levels of success. Throughout the Arab Spring, social media played a key role, Social Media was not only a platform to manifest opinion, it was a public sphere - virtual and imaginary - that allowed and contributed to the bonding of social capital between the actors and their ideas. Social media, therefore, created connections and activations that would not have occurred otherwise, validating all the communication and networking channels and the non-physical and fiat space that is vitally present in today's society. ${ }^{15}$

One study concluded that "social media in general, and Facebook in particular, provided new sources of information that repressive regimes could not easily control and were crucial in shaping how citizens made individual decisions about participating in protests, the logistics of protest, and the likelihood of success." ${ }^{16}$ The logistics of protest included occupation of public space, like Tahrir Square in Cairo. In the end, Social Media actually became a generator of a physical public sphere that Habermas believed to exist only as a virtual or imaginary community.

Although the long-term effects of the Arab Spring that was led by social media have yet to be known, its short-term consequences varied greatly across the Middle East and North Africa. Yet, with social media's ether-like public sphere, regimes might find it more difficult to deactivate this public realm.

\section{SPACE AS A PHYSICAL PLATFORM WITH NO BOUNDARIES}

An example of space as a physical platform but having no boundaries is the "Free Speech Wall" located on the pedestrian mall of downtown Charlottesville, Virginia.

The City of Charlottesville erected the two-sided monumental slate wall in 2006 directly in front of City Hall. The First Amendment of the United States Constitution is chiseled into a segment of the wall, and the remaining space is a huge chalk board. It measures approximately 54 feet long by 7.5 feet high and provides 108 feet of writing space. Members of the public may express their views, in chalk provided by the city, on any subject they choose. In addition, a podium is located next to the wall, affording a place for citizens to declaim verbally. ${ }^{17}$ 


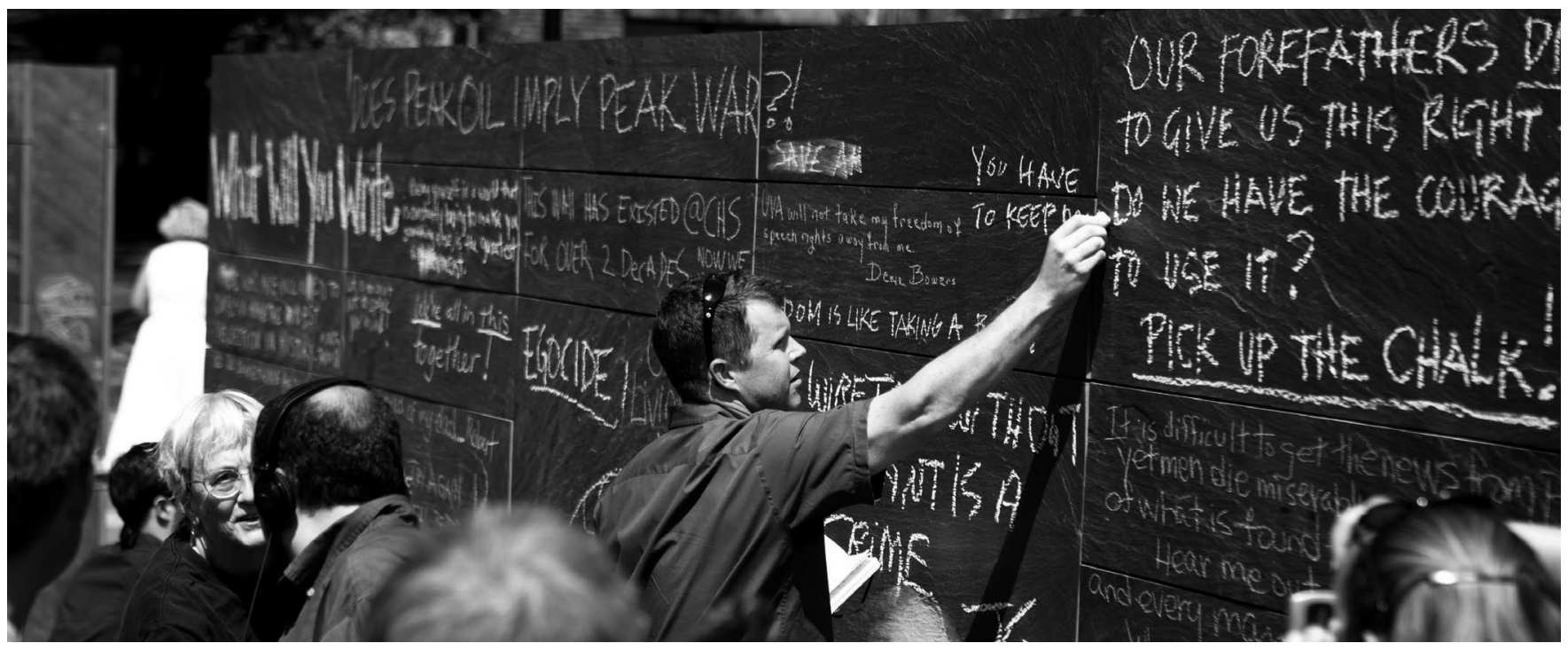

Figure 5: Crowd writing at the "Free Speech Wall" at the pedestrian mall in downtown Charlottesville, Virginia.

The wall commemorates its most famous citizen, Thomas Jefferson, author of the Declaration of Independence and father of the University of Virginia. Citizens responded enthusiasticly, writing their thoughts and ideas on the wall, no matter how offensive or banal. People are free to concur with what is written, or to erase or write over speech with which they disagree. The Free Speech Wall is available to everyone and accommodates the boundless ideas of the citizens of a democracy.

Each person who writes on the wall becomes an activator of the space. Each person who writes over or erases the ideas of others becomes a de-activator, but at the same time becomes an activator of this public space. This simultaneous event may lead to conflicts of ideas, but there is no physical confrontation. Unlike the events of Tiananmen Square or of the Arab Spring, the activator and de-activator are one and the same.

As we stated above, Habermas believed that the public sphere was not confined to identifiable, physical spaces. In the case of The Free Speech Wall, that public sphere of democracy that Habermas identified as developing during the seventeenth century is still identifiable as a virtual community. Although Habermas had grave doubts about the survival of the public sphere in the post modern world, it might be possible to see its survival in these activated spaces. And as Deleuze suggests, the "event" - the written word on The Free Speech Wall has actualized the idea of democracy in an actual community whose democratic ideas have taken a physical manifestation.

The Free Speech Wall, therefore, is a physical platform that allows for the ideas/axioms of the actors to be physically manifested but without the limitations of the spaces - only limited by the fiat boundaries of the ideas - endless possibilities that can take place in the virtual and temporal realms.

\section{CONCLUSION}

Therefore, the interactions and networks that actors form as choreographed events in the spaces, both physical and virtual, happen within the already established public space that is inherent of the city. Nothing exists in isolation, only in relation to someone else or something else, as suggested by Deleuze when he explores the idea that events reshape the concept of connectivity, relationships, and pathways with which these actors affiliate. It is also the basis of social-spatial capital that provides support when it is needed. As Bourdieu states, social capital aggregation of actual and potential resources and ideas linked together support and serve institutional acts, creating a stable relationship among its members.$^{18}$ The process of activation and de-activation, therefore, occurs in the "change" of ideas and is manifested in the space because it is only here where the events can be actualized.

It is this activation and deactivation of space that we have described that leads us to a hypothesis - that societies possess both actual and virtual public space that can be activated through the power of events. These events can be deactivated by a disruptive autocratic power, or they can be developed to have a stronger, more resilient virtual public realm. In addition these events can be simultaneously activated and deactivated without creating physical confrontation.

Public space has the ability to accommodate political demonstrations that activate the space by the nature of the idea. It is often the case that this activation comes with positivism, an allure of thought and the act of expression on the part of the activators. This positivism, however, can often be interrupted not by a single action from a hostile actor or regime, nor by an opposing idea; but rather by the truncated fallacies of the institution itself that does not allow expression to take place. It is these types of truncated ideas that, regardless of affiliation 
or integrity, persist and de-activate the space, disrupting the spatial boundaries, the form and the relationships that are created. It is at this instance that the public space atrophies and becomes powerless because of the mere activation of this same space. Although the actors are still present and they form the critical mass, an aggregation of potential resources and ideas that drive the same message in a single instance, the value and need of the public space is being polluted by false equivalencies.

Nonetheless, societies and their actors - no matter their affiliation - can and will activate and de-activate these platforms, and it is the directness of these actors that must surpass any choreographed event for the activation of the space to take place. Therefore, the most notable public space will be recognized not only by its formal geometries, but also by its ability to accommodate, both physically and metaphorically, the various expressions of a society, regardless of its regime.

\section{ENDNOTES}

1. On Post Structuralism, see Giles Deleuze and Felix Guattari, A Thousand Plateaus, trans. Brian Massumi (Minneapolis: University of Minnesota Press, 1993). On Critical Theory, see Raymond Geuss, The Idea of a Critical Theory Habermas and the Frankfurt School (Cambridge University Press, 1981). On Social Capital Theory, see Pierre Bourdieu, "The Forms of Capital," in
Handbook of Theory and Research for the Sociology of Education, ed. $J$. Handbook of Theory and Research for the Sociology
Richardson (New York: Greenwood, 1986), 241-258.

2. Guttari Deleuze, A Thousand Plateaus, 448-473.

3. Safra, J. New Encyclopaedia Britannica, 15th ed., s.v. "Tiananmen Square" Chicago: Encyclopaedia Britannica Inc., 2003.

4. Ibid. On the May Fourth Movement, see Jeffrey N. Wasserstrom, "Chinese Students and Anti-Japanese Protests, Past and Present," World Policy Journa no. 22.2 (2005): 59-65. Radhey Shyam Chaurasia, History of Modern China (New Delhi: Atlantic, 2004), 256

5. Safra, Tiananmen Square, 752

6. Jeffrey T. Richelson and Michael L. Evans, eds. Tiananmen Square, 1989: The Declassified History, National Security Archive Electronic Briefing Book No. 16. (Washington, DC: George Washington University, 1999). Accessed July 27,
2018. https://nsarchive2.gwu.edu/NSAEBB/NSAEBB16/

7. Louisa Lim, The People's Republic of Amnesia: Tiananmen Revisited (New York: Oxford University Press, 2014), 96

8. Ibid.

9. Ibid.

10. Jürgen Habermas, The Structural Transformation of the Public Sphere: An Inquiry into a category of Bourgeois Society (Cambridge: MIT Press, 1991), 175-177

11. Joseph Massad, "The 'Arab Spring' and other American seasons," Al Jazeera, August 30, 2012, https://www aljazeera com/indepth/opinion/2012/08/2012 82972539153865.html

12. Kareem Fahim, "Slap to a Man's Pride Set Off Tumult in Tunisia," Jan. 21, 2011, New York Times, https://www.nytimes.com/2011/01/22/world/ africa/22sidi.html

13. Asef Bayat, Revolution without Revolutionaries: Making Sense of the Arab Spring (Stanford: Stanford University Press, 2017), 8-10.

14. See announcement at Nobelprize.org. 9 October 2015. The Tunisian National Dialogue Quartet consisted of: The Tunisian General Labor Union; The Tunisian Confederation of Industry, Trade and Handicrafts; The Tunisian Human Rights League; and The Tunisian Order of Lawyers.

15. Asef Bayat, Revolution without Revolutionaries, 142-148.

16. Zeynep Tufekci and Christopher Wilson, "Social Media and the Decision to participate in Political Protest: Observation from Tahrir Square," Journal of Communications 62, no. 2 (April 2012): 363. http://citeseerx.ist.psu.edu/ viewdoc/download?doi=10.1.1.395.184\&rep=rep1\&type=pdf

17. The Thomas Jefferson Center for the Protection of Free Expression, http:// tjcenter.org/free-speech-monuments/

18. Bourdieu, "The Forms of Capital," 248-249 